This is the final peer-reviewed accepted manuscript of:

Villotti, P., Corbière, M., Dewa, C. S., Fraccaroli, F., Sultan-Taïeb, H., Zaniboni, S., \& Lecomte, T. (2018). A serial mediation model of workplace social support on work productivity: The role of self-stigma and job tenure self-efficacy in people with severe mental disorders. Disability and Rehabilitation, 40(26), 3113-3119.

The final published version is available online at:

https://doi.org/10.1080/09638288.2017.1377294

Rights / License:

The terms and conditions for the reuse of this version of the manuscript are specified in the publishing policy. For all terms of use and more information see the publisher's website.

This item was downloaded from IRIS Università di Bologna (https://cris.unibo.it/)

When citing, please refer to the published version. 


\section{A serial mediation model of workplace social support on work productivity: the role of self-stigma and job tenure self-efficacy in people with severe mental disorders}

Purpose. Compared to other disabilities, people with a severe mental illness face the greatest stigma and barriers to employment opportunities. This study contributes to the understanding of the relationship between workplace social support and work productivity in people with severe mental illness working in Social Enterprises (SE) by taking into account the mediating role of self-stigma and job tenure self-efficacy.

Methods. 170 individuals with a severe mental disorder employed in a SE filled out questionnaires assessing personal and work related variables at Phase 1 (baseline) and Phase 2 (6 month follow-up). Process modeling was used to test for serial mediation.

Results. In the SE workplace, social support yields better perceptions of work productivity through lower levels of internalized stigma and higher confidence in facing job-related problems. When testing serial multiple mediations, the specific indirect effect of high workplace social support on work productivity through both low internalized stigma and high job tenure self-efficacy was significant with a point estimate of $1.01(95 \% \mathrm{CI}=.42,2.28)$.

Conclusion. Continued work in this area can provide guidance for organizations in the open labor market addressing the challenges posed by the work integration of people with severe mental illness.

Keywords: severe mental illness; social enterprise; self-stigma; social support; work productivity. 


\section{A serial mediation model of workplace social support on work productivity: the role of self-stigma and job tenure self-efficacy in people with severe mental disorders}

Compared with other disabilities, people with a severe mental illness face the greatest barriers to employment opportunities given the considerable amount of stigmatization in the workplace [1]. This is problematic since work is a leading factor in promoting recovery, particularly in facilitating social integration and citizenship. Discrimination in hiring, difficulties in job retention, and running into snags when returning to work, are well documented realities that people with severe mental disorders experience [2]. Severe mental disorders are also commonly associated with difficulties in terms of work-related productivity [3].

A large number of factors and reasons that contribute to making the working situation difficult for people with severe mental illness have been identified [4]. A leading factor is the limited access to supportive and non-discriminatory workplaces [5]. Receiving social support at work is important because it increases the workers' selfconfidence while creating feelings of attachment to the organization, and positive selfbeliefs at work [6]. Conversely, stigma in the workplace is harmful both directly as a result of discrimination from coworkers and supervisors, and through the internalization of these attitudes and beliefs by the person who is being stigmatized (i.e. self-stigma) [7]. Self-stigma is associated with a diminished self-esteem and poor self-efficacy, which in turn leads to the "why try" effect, i.e. the belief of not being capable to work [8].

Among the services and programs developed to help vulnerable workers enter into the work force, social enterprises (SE) have been found to have features that effectively promote work integration and job tenure for people with severe mental illness: high levels of workplace social support, availability of numerous work 
accommodations and natural support, and a work environment characterized by less discrimination and stigma, to name a few [9]. In their systematic review, Roy and colleagues [10] report evidence that SE represents an effective model for supporting people who struggle to integrate the labor market, by enhancing their skills and employability, as well as by increasing their self-esteem. SE also plays a critical role in reducing public stigmatization by demonstrating that people with psychiatric disorders can be capable and productive workers [11].

With the general aim of better understanding the underlying processes influencing employment success for people with severe mental illness, we examined how the relationship between workplace support and work productivity may be contingent on self-stigma and self-efficacy beliefs (such as confidence in dealing with problems related to job maintenance) systems. Specifically, this study investigates the mediating effects of self-stigma and job tenure self-efficacy on the relationship between perceived social support from supervisor and co-workers and self-reported work productivity in the context of SE. Learning more about which factors influence work achievement (i.e., productivity) in people with severe mental illness has the potential to contribute to improve their work (re-)integration process within the labor market, and thus positively impact on their recovery [12]. In the next sections of the paper, we develop our hypotheses based on the theoretical background, and subsequently we present and discuss the method and results of this study conducted in Canada.

\section{Development of hypotheses}

\section{The relationship between social support and work productivity.}

There is evidence that severe mental disorders are associated with work-related productivity losses, especially in terms of absenteeism (i.e., sickness leave), 
presenteeism (i.e., being at work but not being productive), and the spillover effects on coworkers and supervisors, namely tension and conflicts between colleagues [3]. Mental illness is linked to high indirect costs associated with days of work loss and work impairment, with about $48 \%$ of the cost of psychiatric disability attributed to diminished work productivity [13]. Loss of productivity as a consequence of a psychiatric disorder is also related to reduction in output, higher error rates, increased amount of accidents, poor decision-making, and deficits in planning work [14]. Many individuals who experience severe mental illness face functional limitations in the workplace due to cognitive difficulties such as concentration, memory recall and problem solving [15-16], with subsequent impact on productivity [13]. For example, recent studies revealed a strong association between depressive symptoms and decreased productivity and performance deficits at work [17-19]. Concerns about work capability and productivity, such as poor quantity and quality of work, brief tenure, absenteeism, can also fuel prejudicial and discriminating attitudes from employers and coworkers [20-23].

Multiple factors can influence, positively or negatively, the work functioning of people with mental illness [24]. Among them are individual factors (e.g., severity of symptoms and self-esteem), and environmental factors (e.g., organizational constraints, supported supervision and work accommodations). The literature suggests that social support at work for instance can help improve work productivity as well as the individual's satisfaction and performance at work [25-27]. Social support at work can also reap other benefits, including attachment to the organization, reduced workplace conflicts, increased self-confidence and positive self-beliefs [6]. Difficulties integrating into work for individuals with psychiatric disorders are especially flagrant in discriminatory workplaces characterized by unsupportive relationships with coworkers 
and supervisors [21]. According to Baum \& Neuberger [28] individuals with a mental illness consider their social support at work, namely with supervisors and coworkers, as essential for helping them integrate at work. Other studies also report that significant relationships at work and social encouragement are leading factors in facilitating the work integration of people with mental disorders [29-31], as well as their job satisfaction [32].

On the basis of this evidence, we propose a first hypothesis that there is a positive and direct link between the employee's perceived social support from supervisor and coworkers, and perceived work productivity in our sample of workers with severe mental illness employed in SEs (Hypothesis 1).

\section{Mediating role of self-stigma.}

People with severe mental illness are among the most marginalized members of our society; mental illness stigma is an undesirable hallmark that leads to negative consequences such as poverty and unemployment [33]. Theoretical and empirical evidence suggests that there is a harmful link between stigma and self-concepts such as self-esteem and self-efficacy [34-40]. The harm caused by stigma is not just a direct result of the prejudice and discrimination perpetrated by others but is also the product of the internalization of these public attitudes and beliefs by the stigmatized person [7]. Self-stigma is specific to those with mental illness [36; 41], and can be defined as perceived stigma, meaning the individual's (1) recognition that people are prejudiced and will discriminate against them because of their mental illness [36], and the discriminated individuals' (2) reactions of turning the stigmatizing attitudes against themselves [33]. Thus, it is not simply the objective level of stigma and discrimination that an individual is exposed to, but also the subjective perception of being devalued and marginalized that directly affects a person's cognition, emotion and behavior [7]. 
Low self-esteem and poor self-efficacy are primary examples of the negative consequences of self-stigma [42]. Applying or internalizing stereotypes not only damages self-esteem and lessens self-efficacy, but it also leads to the "why try" effect [43]. Fear of rejection by others is another factor that limits self-stigmatized individuals from pursing life opportunities [44]. This is especially evident in the working context. Self-stigma leads employees with severe mental illness to feel they are not "good enough", that they are not competent or worth it, or that they can not be successful, or keep up with the demands of the job because of their mental health condition [45]. Furthermore, there is evidence that the work environment has the potential to exacerbate or lessen self-stigma. On the one hand employees are more likely to self-stigmatize if their work context uses discriminatory terms for people with mental illness [46]. On the other hand, social support at work can reduce self-stigma [33]. Indeed, good relationships at work can help self-stigmatized individuals to join and enjoy teamwork and bolster organizational loyalty [46].

On the basis of these considerations, we hypothesize that self-stigma is a mediator of the relationship between workplace support and work outcomes. More specifically, we hypothesize an indirect negative effect of self-stigma on the link between social support from supervisor and coworkers and self-reported work productivity (Hypothesis 2).

\section{Mediating role of job tenure self-efficacy.}

Self-efficacy is defined as the individuals' beliefs about their capabilities to produce designated levels of performance [47-48]; it influences the way people feel, think, motivate themselves, and behave. It is a robust construct that has been generalized from its clinical origins [47] to a range of situations, including the work environment [49]. Self-efficacy can explain differences in performance between individuals of similar 
ability because it affects their goals, behaviors and perseverance at work [50]. Evidence from the literature [51-52] indicates a positive association between self-efficacy and productivity. Thus, individuals with a strong sense of efficacy generally report high levels of confidence in their capabilities to master difficult tasks, while people who doubt their capabilities tend to shy away from challenges. The term "job tenure selfefficacy" has been used to describe the confidence an employee with a mental illness has in his/her ability to deal with job tenure-related problems [53].

Thus, we posit that job tenure self-efficacy mediates the relationship between workplace support and perceived work productivity. More particularly, we hypothesize a positive effect of higher levels of social support from supervisor and coworkers on the worker's perception of being productive at work, through stronger feelings of confidence in their ability to overcome problems that arise at work (Hypothesis 3).

\section{Serial mediation hypothesis.}

Self-efficacy beliefs develop as a result of interpreting information cues, such as previous experiences [47]. When exposed to discrimination and stigma, self-confidence suffers [44]; thus, concerns about performance at work may arise because of internalized stigma. Consequently, our final proposition situates social support at work as a predictor of work productivity that is serially mediated by internalized beliefs of being stigmatized and discriminated against, and negative beliefs related to capability to deal with problems that arise at work. More specifically, we propose that workplace support will indirectly influence perceived work productivity through the mediators of self-stigma and self-efficacy at work (Hypothesis 4).

A visual representation of study's hypotheses is reported in figure 1 . 


\section{Method}

\section{Participants and procedure}

Data used for this study was collected from a larger research project related to work integration of people with severe mental disorders employed in social enterprises (SE) located in Canada. Participants answered a battery of questionnaires that collected information about demographics, workplace social support and self-stigma - at Phase 1 (baseline). Information on work outcomes - such as job tenure self-efficacy and perceived work productivity - was gathered at 6-month follow-up. The research project was reviewed and approved by the ethic boards of the Centre intégré universitaire de santé et de services sociaux de l'Estrie - Centre hospitalier universitaire de Sherbrooke. Participants received an honorarium for participating in the study and were recruited through SE directors who briefly described the research project to employees who fit the inclusion criteria. The inclusion criteria were: being 18 years or older, being employed in a SE, ability to speak French or English, and self-identification as having a severe mental disorder. Employees interested in participating in the study were invited to contact the research coordinator.

Data was collected in the greater Montreal area, in Québec Canada. Table 1 summarizes participants' characteristics. Our sample ( $\mathrm{n}=170)$ was mostly middle aged single individuals who reported having a psychotic disorders in the schizophrenia spectrum.

---Table 1 about here---

\section{Measures}

For the purpose of this study, we focused only on the data stemming from two scales administered at baseline (i.e., workplace social support and self-stigma) and two scales 
administered at the 6-month follow up phase (i.e., job tenure self-efficacy, and perceived work productivity).

\section{Workplace social support.}

To gather information about perceived workplace social support we used the social support dimensions scale of Karasek's Job Content Questionnaire [54]. This scale measures two dimensions of social support: one related to social support from the supervisor (6 items, e.g., "My supervisor is helpful in getting the job done"), and one related to social support from coworkers (5 items, e.g., "People I work with encourage each other to work together"). All items are scored on a 5-point scale ranging from 1 (not at all) to 5 (fully). Alpha in the study was .83.

\section{Self-stigma.}

To measure the subjective experience of stigma we used the Internalized Stigma of Mental Illness scale [55]. This is a 29-item questionnaire consisting of 5 subscales: alienation, stereotype endorsement, discrimination experience, social withdrawal, and stigma resistance (reverse scored). Items were scored on a 4-point scale ranging from 1 (strongly disagree) to 4 (strongly agree) and were summed to provide one measure of internalized stigma. Higher scores suggest worse experiences of stigma. Alpha in the study was .91 .

\section{Job tenure self-efficacy.}

We used the 7 items of the Job Tenure Self-Efficacy scale [53] to determine personal confidence in dealing with work problems, with a specific focus on job tenure (e.g., "How certain are you that you can succeed in keeping employment?"; "How certain are you that you will be able to solve problems that could come up at work?"; "How certain are you that you will be able to meet the demands of your job?"; $\alpha=.81$ ). All items were 
scored on a 5-point scale ranging from 1 (not at all certain) to 5 (completely certain). Higher scores indicate greater job tenure self-confidence.

Work productivity.

Perceived work productivity was measured using the Endicott Work Productivity Scale [56]. This scale consists of 25 items covering four productivity areas: attendance (absenteeism and time on task); quality of work, performance capacity, and personal factors (social, mental, physical, and emotional). Items are scored on a 5-point scale ranging from 0 (Never) to 4 (Almost always). Reverse-score of all items were computed to build a global score, where higher score at the scale equals to higher perception of productivity. Alpha in this study was .89.

\section{Control variables.}

Participants were asked for their age (in number of years), gender (female vs male), level of education (less than high school, high school or college diploma, university or more), diagnosis (schizophrenia spectrum vs others), length of job tenure (in number of months), and hours worked per week (less than 21, between 21 and 35, more than 35). Age was the only variable found to be significantly linked to the dependent variable 'Work productivity' $(r=.24, p<.01)$. Accordingly, age was introduced as control variable in the subsequent analyses [57].

\section{Data analysis}

SPSS software version 21 was used to perform the data analysis. Descriptive statistics were calculated to characterize the study sample and variables. Pearson's productmoment correlation was computed to examine the directions and correlations among individual (i.e., age, gender, education, diagnosis) and work-related (i.e., length of job tenure, hours worked per week) characteristics and our study variables (i.e., social 
support from supervisor and coworkers, self-stigma, job tenure self-efficacy, work productivity).

To test our hypothesis that self-stigma and job tenure self-efficacy act as serial mediators of the relationship between workplace social support and perceived work productivity, we used the SPSS PROCESS macro, model 6 [58]. Five thousand bootstrap sample were used to create $95 \%$ bias-corrected and accelerated (BCa) confidence intervals to test the significance of indirect effects, which are significant at $\mathrm{p}=.05$ if the $95 \%$ confidence interval does not include zero.

\section{Results}

Means, standard deviations, and correlations regarding the study variables are displayed in table 2. All correlations were in the hypothesized directions: workplace social support was found to be positively related with perceptions of perceived work productivity $(r=$ $.25, \mathrm{p}<.01)$ and higher job tenure self-efficacy $(r=.37, \mathrm{p}<.001)$, and negatively related to self-stigma $(r=-.37, \mathrm{p}<.001)$. Self-stigma was negatively related to job tenure selfefficacy $(r=-.44, \mathrm{p}<.001)$ and work productivity $(r=-.37, \mathrm{p}<.001)$. Finally, job tenure self-efficacy was found to be positively related to higher levels of perceived work productivity $(r=.44, \mathrm{p}<.001)$. Older age was found to be positively related to longer job tenure in the SE $(r=.29, \mathrm{p}<.01)$ and to higher perceptions of perceived work productivity $(r=.24, \mathrm{p}<.01)$.

--- Table 2 about here ---

Results of the serial mediation analyses are displayed in figure 2. Confirming Hypothesis 1, we found a positive direct effect of workplace social support on high levels of perceived work productivity (total effect; $\beta=6.09, t=2.65, p=.01$ ), accounting for an explained variance of .11. As predicted, however, this relationship became non-significant when both mediators were included in the model (total direct 
effect; $\beta=.97, t=.42, p=n s)$. Age was also found to be a predictor of levels of perceived work productivity $(\beta=.26, t=2.58, p=.01)$. The total indirect effect was significant with a point estimate of $5.12(95 \%$ confidence interval $(\mathrm{CI})=2.88,8.44)$, with an explained variance of .27. Confirming Hypothesis 2, the specific indirect effect through low internalized stigma was significant with a point of estimate of 1.87 (95\% CI $=.55,3.84)$. The specific indirect effect through high job tenure self-efficacy was significant with a point of estimate of $2.18(95 \% \mathrm{CI}=.73,4.71)$, confirming Hypothesis 3. Finally, we tested the indirect effect of workplace social support on perceived work productivity through both self-stigma and job tenure self-efficacy. The relationship was significant with a point estimate of 1.01 (testing serial multiple mediation; $95 \% \mathrm{CI}=.42$, 2.28). Thus, Hypothesis 4 was also confirmed.

To summarize, results from our study demonstrate that there is an indirect relationship between high workplace social support in the SE context (perceived social support from both supervisor and coworkers) and high perception of being productive. This link is fully mediated by lower levels of self-stigma and higher levels of job-tenure self-efficacy.

---Figure 2 about here---

\section{Discussion}

This study examined the relationship between workplace support and perceived work productivity in workers with severe mental illness employed in SEs, with specific focus on self-stigma and job tenure self-efficacy. Severe mental illnesses account for considerable work disability [59] and reduced job productivity [60]. One of the problems workers with mental illness face, which puts them at risk for low productivity, is poor support from colleagues and supervisors [61-62]. Self-stigma is also recognized 
as a potential obstacle to work participation [45], whereas self-efficacy beliefs have a significant and positive impact on job maintenance [63].

We hypothesized that internalized stigma would decrease the individuals' selfefficacy in dealing with work-related problems, especially problems that might lead to losing employment prematurely-- an often-reported difficulty with this population [64]. This is because self-stigma is commonly found to lead to negative emotional reactions (i.e., low self-efficacy) in people with mental illness [33], which in turn would lead to behavioral responses, such as failing to pursue work requirements (e.g., work productivity). Despite the fact that self-stigma is a common consequence of developing a mental health problem, being aware that stigmatizing views exist does not necessarily lead to their internalization [65]. Many individuals with severe mental illness are aware that stereotypes, prejudice and discrimination toward people with mental illness exist and yet they neither display self-stigma beliefs, nor reductions in self-esteem and selfefficacy [65]. In fact, depending on the situation, persons with mental illness may react to stigma with low self-esteem and diminished self-efficacy, but also with a sense of energy and willingness to react to contrasts stigma, or showing a seeming indifference to it [33].

In our main hypothesis, internalized stigma and job tenure self-efficacy serially and fully mediates the negative relationship between workplace support and low levels of perceived work productivity. The findings of this study support and extend prior research on the positive effect of perceived support from supervisor and coworkers in promoting work outcomes in workers with severe mental illness [e.g., 32] suggesting that self-stigma undermines the individuals' job related confidence with decreased success in work productivity. Our results support the need for future research on work disability focusing on a better understanding of stigma and other factors at work [59]. 
Our study advocates for investigating self-stigma and job-related self-efficacy beliefs, which respectively undermine and promote the positive effect of perceived social support at work. Our study also adds to the limited but growing body of literature on employment in SEs [e.g., 10]. As such, it illustrates the potential of the social enterprise model in supporting people with severe mental illness integrate into work, with the help of workplace support, diminished perceptions of being discriminated, enhanced skills and employability, as well as increased self-efficacy at work.

Our study has some limitations that should be taken in account. First of all, despite the fact this limitation is shared with many others studies in the field, our study relies exclusively on self-reported data. Furthermore, we only focused on the perspective of employees, while it would have been interesting to investigate perceptions of other stakeholders involved in the process of work integration of people with severe mental illness (for example, the immediate supervisor), especially in terms of work productivity. This would allow researchers to have a broader and more comprehensive picture of the situation. Additionally, the scores on perceived selfstigma were, on average, low and restricted in range; this reflect the nature of the social enterprise's working context, which is characterized by less discrimination and stigma toward mental health problems. SEs represent a unique environment in which to investigate processes underlying the work integration of individuals with mentally illness, although the generalizability of the results to other work contexts may be limited. It is also important to note that different types of SEs exist; our study took place in the specific context of adapted enterprises, in which vulnerable individuals (such as people with severe mental disorders) work side by side with people who do not have a diagnosis of mental illness. Thus, it is possible that social enterprises which enroll only people with mental disorders, such as consumer/survivor run businesses, could obtain 
different results. Furthermore, the model presented in the study fails to take into account factors that may make internalized prejudices and levels of job related self-efficacy fluctuate, such as previous work experiences. Indeed, perceptions of stigma and beliefs about one's capacities depend on situations and may not be consistent over time. These limitations notwithstanding, the present research provides new evidence explaining the existing relationship between workplace support and work productivity and sets the stage for additional studies to further test these relevant links.

As a final comment, results of this study show how in the context of social enterprises, higher perceptions of work productivity are influenced by the provision of workplace social support through low levels of internalized stigma and high confidence in facing problems related to job tenure. Continued work in this area can provide guidance for organizations in the open labor market addressing the challenges posed by the work integration of people with severe mental illness. 
References

[1] Hipes C, Lucas J, Phelan JC, White R. The stigma of mental illness in the labor market. Soc Sci Res. 2016; 56:16-25.

[2] Schur L, Colella A, Adya M. Introduction to special issue on people with disabilities in the workplace. Int J Hum Resour Man. 2016; 27(14):1471-1476.

[3] Dewa CS, McDaid D. Investing in the mental health of the labor force:

Epidemiological and economic impact of mental health disabilities in the workplace. In: Schultz IZ, Rogers ES, editors. Work accommodation and retention in mental health. New York: Springer, 2011. p. 33-51.

[4] Krupa T. Employment and serious mental health disabilities. In: Schultz IZ, Rogers ES, editors. Work accommodation and retention in mental health. New York: Springer, 2011. p. 91-101.

[5] Paluch T, Fossey E, Harvey C. Social firms: building cross-sectoral partnerships to create employment opportunity and supportive workplaces for people with mental illness. Work. 2012; 43:63-75.

[6] Chan ANW. Social support from improved work integration: Perspectives from Canadian social purpose enterprises. Soc Enterp J. 2015; 11(1): 47-68.

[7] Lauber C. Stigma and discrimination against people with mental illness: a critical appraisal. Epidemiol Psichiatr Soc. 2008; 17(1):10-3.

[8] Corrigan PW, Larson JE, Rüsch N. Self-stigma and the "why try" effect: Impact on life goals and evidence-based practices. World Psychiatry. 2009; 8:75-81.

[9] Villotti P, Zaniboni S, Fraccaroli F. Les entreprises à économie sociale en Italie (Social cooperatives in Italy). Enchéphale. 2014; 40 Suppl 2:57-65. 
[10] Roy MJ, Donaldson C, Baker R, et al. The potential of social enterprise to enhance health and well-being: A model and systematic review. Soc Sci Med. 2014; 123:182193.

[11] Ho AP, Chan K. The social impact of work-integration social enterprise in Hong Kong. Int Soc Work. 2010; 53(1):33-45.

[12] Dunn EC, Wewioeski NJ, Rogers ES. The meaning and importance of employment to people in recovery from serious mental illness: results of a qualitative study. Psychiat Rehabil J. 2008; 32(1):59-62.

[13] Chatterji P, Alegria M, Lu M, et al. Psychiatric disorders and labor market outcomes: Evidence from the National Latino and Asian American Study. Health Econ. 2007; 16:1069-90.

[14] Crown C. Stress at work: a guide for employers. UK: Health \& Safety Executive; 1995.

[15] Ettner SL, Frank RG, Kessler R. The impact of psychiatric disorders on labor market outcomes. Ind Labor Relat Rev. 1997; 51(1):64-81.

[16] MacDonald-Wilson K, Rogers ES, Massaro J. Identifying relationships between functional limitations, job accommodations, and demographic characteristics of persons with psychiatric disabilities. J Vocat Rehabil. 2003; 18:15-24.

[17] Beck A, Crain AL, Solberg LI, et al. Does severity of depression predict magnitude of productivity loss?. Am J Manag Care. 2014; 20(8): e294-e301.

[18] Jain G, Roy A, Harikrishnan V, et al. Patient-reported depression severity measured by the PHQ-9 and impact on work productivity: results from a survey of fulltime employees in the United States. J Occup Environ Med. 2013; 55(3):252-258.

[19] Lerner D, Henke RM. What does research tell us about depression, job performance, and work productivity?. J Occup Environ Med. 2008; 50(4):401-410. 
[20] Diksa E, Rogers ES. Employer concerns about hiring persons with psychiatric disability: results of the employer attitude questionnaire. Rehabil Couns Bull. 1997; $40(1): 31-44$.

[21] Stuart H. Mental illness and employment discrimination. Curr Opin Psychiatr. 2006; 19:522-526.

[22] Khalema NE, Shankar J. Perspectives on employment integration, mental illness and disability, and workplace health. Adv Public Health. 2014; Article ID 258614. http://dx.doi.org/10.1155/2014/258614

[23] Shankar J, Liu L, Nicholas D, et al. Employers' perspectives on hiring and accommodating workers with mental illness. Sage Open. July-September 2014; 1-13. [24] Costa-Black KM, Feuerstein M, Loisel P. Work disability models: past and present. In: P Loisel, JR Anema, editors. Handbook of work disability: Prevention and Management. New York: Springer; 2013. p. 71-93.

[25] Depedri S. Determinants and consequences of on-the-job relationships: an empirical analysis of Italian social cooperatives. Journal of Entrepreneurial and Organizational Diversity. 2014; 3(2):49-74.

[26] Jaskiewicz W, Tulenko K. Increasing community health worker productivity and effectiveness: a review of the influence of the work environment. Human Resources for Health. 2012; 10:38.

[27] Morrison R. Informal Relationships in the Workplace: Associations with Job Satisfaction. New Zeal J Psychol. 2004; 33(3):114-128.

[28] Baum N, Neuberger T. The contributions of persons in the work environment to the self-identity of persons with mental health problems: a study in Israel. Health and Social Care in the Community. 2013; 22(3): 308-316. 
[29] Provencher HL, Gregg R, Mead S, et al. The role of work in the recovery of persons with psychiatric disabilities. Psychiatr Rehabil J. 2002; 26(2):132-144.

[30] Henry AD, Lucca AM. Facilitators and barriers to employment: The perspectives of people with psychiatric disabilities and employment service providers. Work. 2004; 22(3):169-182.

[31] Svanberg J, Gumley A, Wilson A. How do Social Firms Contribute to Recovery from Mental Illness? A Qualitative Study. Clin Psychol Psychot. 2010; DOI: 10.1002/cpp.681, published online in Wiley InterScience.

[32] Villotti P, Corbière M, Zaniboni S, et al. Individual and environmental factors related to job satisfaction in people with severe mental illness employed in social enterprises. Work. 2012; 43(1):33-41.

[33] Corrigan PW, Watson AC. The paradox of self-stigma and mental illness. Clin Psychol-Sci Pr. 2002; 9:35-53.

[34] Corrigan PW, Kleinlein P. The impact of mental illness stigma. In: Corrigan PW, editor. On the Stigma of Mental Illness: Implications for Research and Social Change. Washington: The American Psychological Association; 2005.

[35] Corrigan PW, Watson AC, Barr L. The self-stigma of mental illness: Implications for self-esteem and self-efficacy. J Soc Clinl Psychol. 2006; 25(9):875-884.

[36] Link BG. Understanding labeling effects in the area of mental disorders: An assessment of the effects of expectations of rejection. Am Sociol Rev. 1987; 52:96-112. [37] Link BG, Mirotzink J, Cullen FT. The effectiveness of stigma coping orientations: Can negative consequences of mental illness labeling be avoided? J Health Soc Behav. $1991 ; 32: 302-320$.

[38] Rosenfield S. Labeling mental illness: the effects of received services and perceived stigma on life satisfaction. Am Sociol Rev. 1997; 62:660-672. 
[39] Wright ER, Gronfein WP, Owens TJ. Deinstitutionalization, social rejection, and the self-esteem of former mental patients. J Health Soc Behav. 2000; 41(1):68-90. [40] Link BG, Phelan JC. Conceptualizing stigma. Annu Rev Sociol. 2001; 27(1):363385.

[41] Ritsher JB, Phelan JC. Internalized stigma predicts erosion of morale among psychiatric outpatients. Psychiatry Res. 2004; 129(3):257-265.

[42] Watson AC, Corrigan PW, Larson JE, et al. Self-stigma in people with mental illness. Schizophrenia Bull. 2007; 33:1312-1318.

[43] Corrigan PW. Lessons learned from unintended consequences about erasing the stigma of mental illness. World Psychiatry. 2016; 15:67-73.

[44] Corrigan PW, Larson JE, Kuwabara SA. Mental Illness Stigma and the Fundamental Components of Supported Employment. Rehabil Psychol. 2007; $52(4): 451-457$.

[45] Corrigan PW, Powell KJ, Rüsch N. How does stigma affect work in people with serious mental illnesses? Psychiatr Rehab J. 2012; 35(5):381-384.

[46] Gelb BD, Corrigan PW. How managers can lower mental illness costs by reducing stigma. Business Horizons. 2008; 51:293-300.

[47] Bandura, A. Social foundations of thought and action: A social cognitive theory. Prentice Hall: Englewood Cliffs, NJ; 1986.

[48] Bandura, A. Self-efficacy. In: Ramachaudran VS, editor. Encyclopedia of human behavior. New York: 1994: Academic Press; 1994. p. 71-81.

[49] Schyns B, Van Collani G. A new occupational self-efficacy scale and its relation to personality constructs and organizational variables. EJWOP. 2002;11(2):219-241. [50] Gist ME, Mitchell TR. Self-efficacy: a theoretical analysis of its determinants and malleability. Acad Manage Rev. 1992; 17(2):183-211. 
[51] Stajkovic AD, Luthans F. Self-efficacy and work-related performance: A metaanalysis. Psychol Bull. 1998; 124, 240-261.

[52] Cherian JP, Jacob J. Impact of self-efficacy on motivation and performance of employees. International Journal of Business and Management. 2013; 8(14):80-89. [53] Franche RL, Corbière M, Lee H, et al. The Readiness for Return-To-Work (RRTW) scale: Development and Validation of a Self-report Staging Scale in Lost-time Claimants with Musculoskeletal Disorders. J Occup Rehabil. 2007;17:450-472. [54] Karasek RA, Brisson Q, Kawakami N, et al. The Job Content Questionnaire (JCQ): An instrument for internationally comparative assessments of psychosocial job characteristics. Journal of Occupational Health Psychology. 1998; 3(4):322-355. [55] Ritsher JB, Otilingam PO, Grajales M. Psychometric properties of a new measure of internalized stigma. Psychiat Res. 2003; 121:31-49.

[56] Endicott J, Nee J. Endicott Work Productivity Scale (EWPS): A new measure to assess treatment effects. Psychopharmacol Bull. 1997; 33(1):13-26.

[57] Becker TE. Potential problems in the statistical control of variables in organizational research: A qualitative analysis with recommendations. Organizational Research Methods. 2005; 8(3):274-289.

[58] Hayes AF. Introduction to Mediation, Moderation, and Conditional Process Analysis: A regression-based approach. New York: The Guilford Press; 2013 [59] Pransky GS, Fassier JB, Besen E, et al. Sustaining work participation across the life course. J Occup Rehabil. 2016; 26:465-479.

[60] Burton WN, Glenn P, Conti JC, et al. The association of medical conditions and presenteeism. J Occup Environ Med. 2004; 46(6): S38-S45.

[61]Varekamp I, Vries G, Heutink A, et al. Empowering employees with chronic diseases; development of an intervention aimed at job retention and design of a 
randomised controlled trial. BMC Health Serv Res. 2008;8(1):224. doi: 10.1186/14726963-8-224.

[62] Munir F, Randall R, Yarker J, et al. The influence of employer support on employee management of chronic health conditions at work. J Occup Rehabil. 2009; 19(4):333-344.

[63] Hutting N, Engels JA, Staal JB, et al. Development of a self-management intervention for employees with complaints of the arm, neck and/or shoulder (CANS): a focus group study with experts. Journal of Occupational Medicine and Toxology. 2015; 10:9.

[64] Shankar J. Improving job tenure for people with psychiatric disabilities through ongoing employment support. AeJAMH.2005; 4(1).

[65] Hayward P, Bright J. Stigma and mental illness: a review and critique. Journal of Mental Health. 1997; 6:345-354. 
Table 1. Participants' characteristics and employment status.

Demographic or employment status variable

$\mathrm{N}(\%)$ or Mean $[\mathrm{SD}]$

\begin{tabular}{ll}
\hline Gender & \\
Male & $94(55.3)$ \\
Female & $76(44.7)$ \\
Age & $21-64$ \\
$\quad$ Range & $45.58[9.43]$ \\
Average & \\
Diagnosis & $83(49.4)$ \\
$\quad$ Schizophrenia & $85(50.6)$ \\
Other & \\
Marital status & $112(65.9)$ \\
$\quad$ Single & $23(13.5)$ \\
Separated, divorced or widowed & $35(20.6)$ \\
Married, or living with a domestic partner & \\
Education & $91(53.8)$ \\
$\quad$ High school or less & $28(16.6)$ \\
College certificate or diploma & $20(11.8)$ \\
University- level education or higher & \\
Length of job & $72.08[59.14]$ \\
months (average) & \\
Work per week & $24(14.1)$ \\
$\quad$ Less than 21 & $15(8.8)$ \\
Between 21 and 35 & $128(75.3)$ \\
35 or more & \\
Previous work experience & $162(96.4)$ \\
Yes & $6(3.6)$ \\
No & \\
\hline
\end{tabular}

Note. $N=170$. 
Table 2. Means, Standard Deviations, Correlations, and Cronbach Alphas.

\begin{tabular}{lccccccccccc}
\hline & $\mathrm{M}$ & $\mathrm{SD}$ & $\alpha$ & 1 & 2 & 3 & 4 & 5 & 6 & 7 & 8 \\
\hline 1. Gender & - & - & - & & & & & & & & \\
2. Age & 45.58 & 9.43 & - & -.14 & & & & & & & \\
3. Education & - & - & - & -.07 & $.17^{*}$ & & & & & & \\
4. Diagnosis & - & - & - & $.16^{*}$ & -.03 & .08 & & & & & \\
5. Job tenure (months) & 72.08 & 59.14 & - & -.01 & $.29 * *$ & .05 & .11 & & & & \\
6. Hours worked per week & - & - & - & .06 & .07 & -.01 & .11 & .15 & & & \\
7. Social support & 3.27 & .45 & .83 & -.12 & .07 & -.05 & -.10 & -.07 & .01 & & \\
$\begin{array}{l}\text { 8. Self-stigma } \\
\text { 9. Job tenure self-efficacy }\end{array}$ & 1.95 & .47 & .85 & .11 & -.07 & .14 & -.02 & .10 & .03 & $-.37^{* * *}$ & \\
$\begin{array}{l}\text { 10. Perceived work } \\
\text { productivity }\end{array}$ & 19.43 & .84 & .81 & -.05 & .09 & .05 & -.03 & .06 & -.09 & $.37^{* * *}$ & $-.44^{* * *}$ \\
\end{tabular}

Note: Mean, Standard Deviation and Reliability estimates $(\alpha)$ calculated on the total sample $(N=170)$. Gender was coded $1=$ males and $0=$

females. Level of education was coded 1= less than high school, 2=high school or college diploma and 3=university level or higher. Diagnosis

was coded $1=$ schizophrenia spectrum, $0=$ others. Hours worked per week was coded $1=$ less than $21,2=$ between 21 and $35,3=$ more than 35 .

$* p<.05 ; * * p<.01 ; * * * p<.001$ 
Figure 1. Visual representation of study's hypotheses.

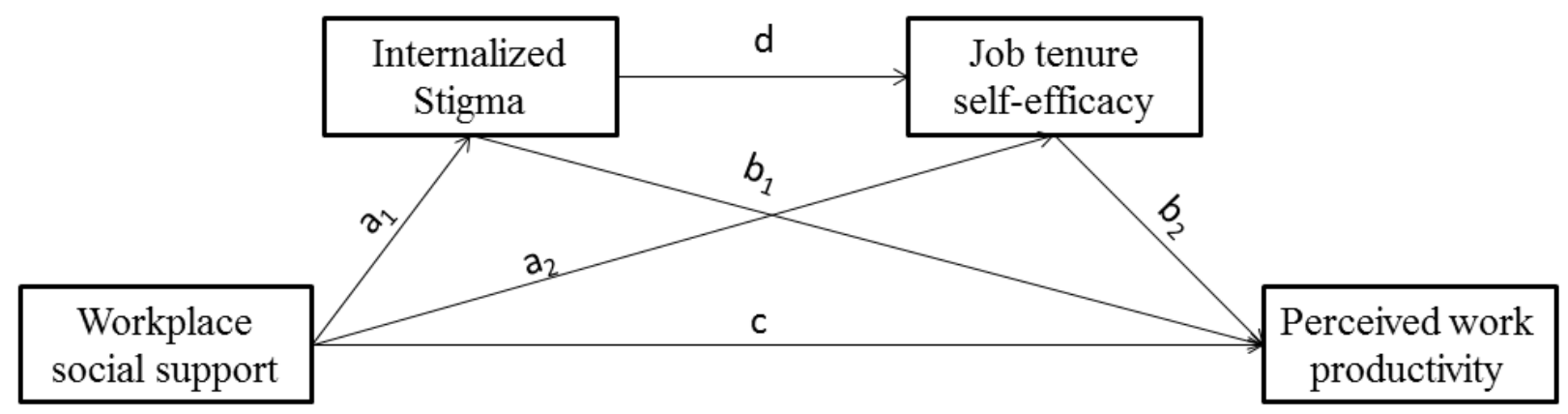

Note. Hypothesis $1(\mathrm{H} 1)=$ total effect of workplace social support on work productivity

(c); Hypothesis $2(\mathrm{H} 2)=$ specific indirect effect through low internalized stigma $\left(\mathrm{a}_{1} \mathrm{~b}_{1}\right)$;

Hypothesis $3(\mathrm{H} 3)=$ specific indirect effect through job tenure self-efficacy $\left(\mathrm{a}_{2} \mathrm{~b}_{2}\right)$;

Hypothesis $4(\mathrm{H} 4)=$ serial multiple mediation $\left(\mathrm{a}_{1} \mathrm{db}_{2}\right)$.

Figure 2. Process results of the study are displayed. Standardized coefficients $(\beta)$ are presented.

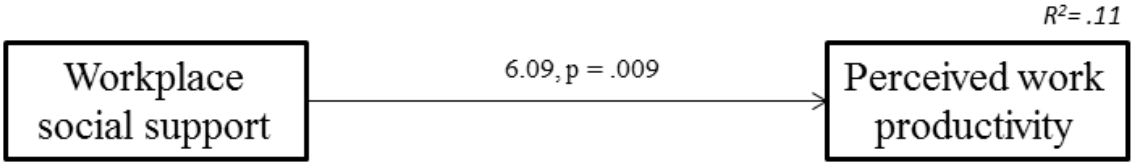

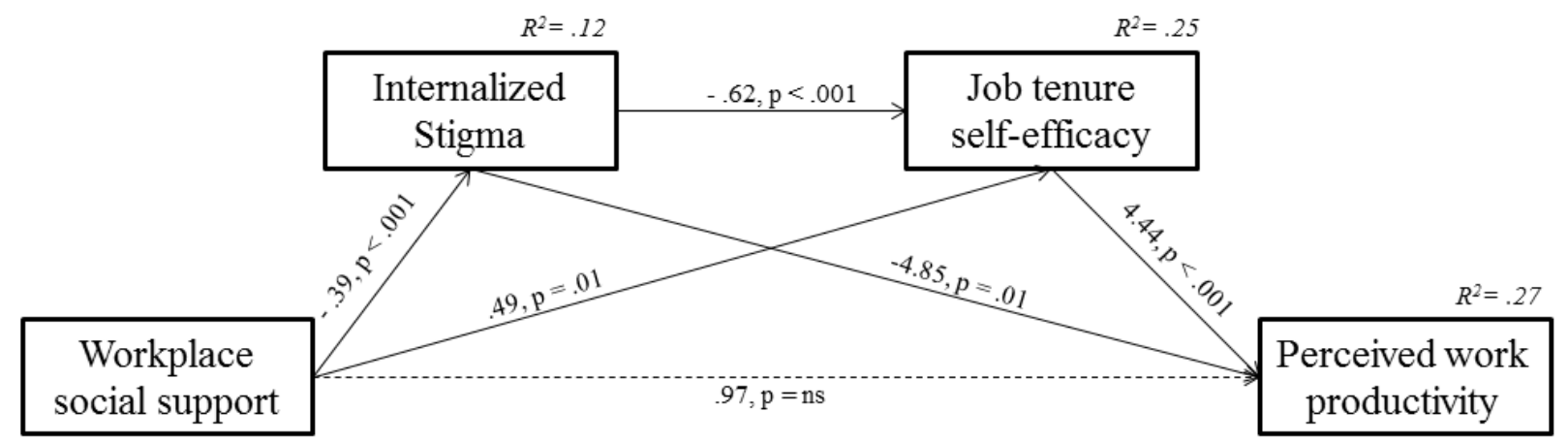

